rabbit, by the in vitro experiments on the phrenic nerve-diaphragm preparation. In the intact mouse (see Fig. 1) it is seen that the myoneural junction is slightly less sensitive to the dimethyl ether compound than to $d$-tubocurarine, but the rate of elimination of the former is slightly less than that of the latter.

The fact that, in the rat in vivo, the duration of action of the dimethyl ether of $d$-tubocurarine iodide is many times greater than that of $d$-tubocurarine, whereas the intensity of its action is only about three times that of $d$-tubocurarine, indicates that the dimethyl ether compound is removed much more slowly than $d$-tubocurarine from its site of action in this species. That removal of both substances is partly effected by the kidneys is shown by the delayed recovery which follows ligation of the renal vessels. It is, however, clear that, in the rat with the kidneys eliminated, a mechanism exists for fairly rapid destruction or removal from the circulation of $d$-tubocurarine, but this mechanism does not operate, or operates very slowly, in the case of the other substance.

The dibenzyl and di-isopropyl ethers of $d$-tubocurarine iodide were prepared by methods similar to that described above. As judged by the ED50 and $L D 50$ in the mouse, the dibenzyl compound possesses about one-third, and the di-isopropyl compound in preliminary experiments about one-half, of the activity of $d$-tubocurarine. In the rat and the rabbit, the dibenzyl compound exhibits about one-half the intensity of action of $d$-tubocurarine. In the rat, the dibenzyl ether gives no evidence of having an action more prolonged than that of $d$-tubocurarine at corresponding dosage-levels.

The dimethyl ether of $l$-bebeerine di-methochloride was prepared from $l$-bebeerine (from Chondrodendrum platyphylum) essentially by the method of King ${ }^{1}$ (cf. Dutcher ${ }^{2}$ and Brazil et al. ${ }^{7}$ ). The ED50 and $L D 50$ of this compound in the mouse are approximately twice those of $d$-tubocurarine. The duration of paralysis in the mouse at two-thirds of the $L D 50$ is approximately equivalent to that caused by $d$-tubocurarine at the same fraction of its $L D 50$. In a Raventós preparation of the rat, $30 \mu \mathrm{gm}$. of the dimethyl ether of $l$-bebeerine dimethochloride reduced the tension of muscular contraction to the same extent as $10 \mu \mathrm{gm}$. of $d$-tubocurarine, but the effect of the bebeerine compound lasted four times as long. It is noteworthy that the dimethyl ether of $l$-bebeerine dimethochloride and its diastereoisomer, the dimethyl ether of $d$-tubocurarine iodide, both exhibit prolonged curarizing action in the rat as compared with $d$-tubocurarine.

We wish to express our thanks to the directors of Messrs. Allen and Hanburys, Ltd., for permission to publish this work; to Mr. C. J. Eastland for originally suggesting that the dimethyl ethers of $d$-tubocurarine and of $l$-bebeerine dimethochloride be synthesized and investigated; and also, to Mr. S. H. Pegg and Miss P. B. Jacks for technical assistance in the pharmacological work.

1 King, H., J. Chem. Soc., 1157 (1939).

${ }^{2}$ Dutcher, J. D., J. Amer. Chem. Soc., 68, 419 (1946).

' Raventos, J., private communication, to be published elsewhere.

- Chou, T. C., Brit. J. Pharmacol., 2, 1 (1947).

- Miller, L. C., and Tainter, M. L., Proc. Soc. Exp. Biol. Med., 57, 261 (1944).

"McIntyre, A. R., “Curare, its History, Nature and Clinical Use", 154 (Chicago, 1947)

' Brazil, O. V., Seba, R. A., and Campos, J. S., Bol. Inst. Vital. Brazil, 5, 79 (1945) (through Chem. Abstr., 41, 3872; 1947).

\section{THE FLOW OF GLACIERS}

A JOINT meeting of the British Glaciological Society, the British Rheologists' Club, and the institute of Metals, held at the Institute of Metals on April 29, had as its main object the bringing together of glaciologists and those physicists and metallurgists who are interested in the theoretical problems of glacier flow. The exchange of experience and ideas between these two groups was a most stimulating feature of the meeting.

The meeting was in two sections. In the first part, with Sir Arthur Smout in the chair, Mr. Gerald Seligman, president of the British Glaciological Society, presented a film illustrating the methods of glacier research in the field used by the Jungfraujoch Glaciological Research Party in 1937 and 1938. The principal aim was to trace the transition of the tiny snow crystals which accumulate at the top of the glacier, first into the compacted glacier snow called 'firn', and then into the larger crystals of glacier ice. To illustrate this transition, slides were shown of photomicrographs taken between crossed nicols in which the growth of the individual crystals could be clearly seen.

The audience was introduced to the terrain investigated by a series of slides which, besides illustrating its purely geographical features, left no doubt about the beauty of the scenery in which the expedition worked. The film showed the construction of the expedition's 'cold laboratory', a small room excavated out of the glacier ice near the summit of the Jung. fraujoch. This laboratory remained at a temperature of $-4^{\circ} \mathrm{C}$. throughout the summer months, and it was here that much of the work on the growth of ice crystals was done. There were, in addition, experiments on the distribution of velocity at the surface of the glacier and on the walls of a tunnel cut into the ice.

Mr. Seligman also described the work of the expedition last summer on the same subject. He pointed out that very large crystals $(10 \mathrm{~cm}$. or more in diameter) are only found in the 'dead' (nonflowing) ice left behind in patches when a glacier recedes. In flowing ice the crystals are much smaller (up to 1-2 cm. diameter). In his view, time and radiation (heat and light) are the main factors influencing the crystal size. The increase in crystal size from the head of a glacier to the snout is due to the fact that the crystals in the lower parts of the glacier are older than those higher up. To support this, he showed graphs giving the crystal sizes at the centres of the snouts in eleven glaciers plotted first against the length of travel and secondly against the mean angle of the glacier slope. The influence of radiation was shown by the fact that in the vicinity of an electric lamp in an ice cave the crystals were abnormally large. It appeared from Mr. Seligman's remarks that both grain growth and work recrystallization play a part in determining the size of the ice crystals. The large size of the crystals in dead ice is a consequence of the former process, and the abnormally rapid growth of new crystals near the end of the Upper Grindelwald Glacier is an example of the latter.

For the second part of the meeting, Dr. Richard Seligman took the chair, and the discussion on the flow of ice was opened by Dr. M. F. Perutz, who gave a short summary of the current theories. The main feature of the movement of a glacier, he said, is that it does not move rigidly, but that the centre 
travels faster than the sides. Attempts made to treat the ice mathematically as a liquid of constant viscosity flowing in an evenly inclined channel have had some success, although there are also discrepancies. Lagally's development of Somigliana's theory has led to a relationship between the surface velocity at the centre of a glacier and its depth. Starting from the measured value of the velocity, the depth of the Pasterze in Austria, for example, has been calculated to be $280 \mathrm{~m}$., a value confirmed by seismic soundings. In spite of this agreement, however, these theories have started from false premises, for ice is far from behaving as a liquid of constant viscosity. On the contrary, small differences in shear stress can produce large changes in velocity.

After referring to the importance of the large-scale thrust planes studied by Mr. W. V. Lewis, Dr. Perutz showed photographs taken by Dr. Winterhalter of Zurich of a thin sheet of ice placed between crossed nicols and loaded by sustained tension. The deformation of the constituent grains could be watched and there were indications of both gliding and mechanical twinning.

Dr. E. Orowan, who spoke next, took as his starting point the simplest laws of the theory of the plastic behaviour of crystalline bodies, and showed how many of the phenomena in glaciers, which at first sight appear to contradict common sense, can be under. stood from this point of view. Common sense in these matters is largely the accumulated experience of the behaviour of viscous liquids; but ice, like crystalline solids in general, is not a viscous but a plastic material. The flow of ice and that of viscous liquids corresponds to two distinct physical mechan. isms and laws of irreversible deformation. However, the stress-strain relationship customarily used in engineering to describe the plastic behaviour of materials is not a complete description, because it omits time effects. The rate of change of strain with time under constant stress, that is, creep, is of primary importance in the flow of glaciers. Andrade has distinguished between two types of creep, the first dying away rapidly with time after the application of a stress, and the second being a permanent flow, the viscous creep. In glaciers, viscous creep seems the more significant part.

The idealized behaviour of ice on which Dr. Orowan bases his theory is that flow is negligible up to a certain critical stress, the yield stress. After that point a slight further increase of stress produces an extremely rapid increase of the rate of flow. The coefficients of viscosity 'measured' in experiments on glaciers are, he believes, of little physical significance. The three-dimensional nature of the stress system in large masses of ice is an important factor. Yielding depends on a critical value of the difference of two principal stresses being attained; pure hydrostatic tension or compression has no appreciable effect, contrary to a view often expressed by glaciologists.

The first simple problem Dr. Orowan discussed was that of a rectangular slab of ice resting on an inclined plane. Movement would be by shear in the lowest layer, and to each angle of slope would correspond one thickness of ice in plastic equilibrium. This implied that, when the ice reached a more steeply sloping part of the glacier bed, its thickness would be greater than the equilibrium thickness and this part of the ice would exert a pressure on the ice in front of it. This longitudinal pressure is the funda. mental physical quantity in the flow; when it reaches a critical value, depending on the compressive yield stress of ice, longitudinal compression will occur. The observed thrust planes are a consequence of the compression; one cannot say exactly how they arise, but that they are a common phenomenon can be seen by attempting to clear away a fall of snow by pushing at it horizontally.

The thrust plane is usually the plane next to the bed of the glacier. However, at sills, that is, at places where there is a sudden fall in the level of the bed, other thrust planes become geometrically possible. This, combined with the fact that the thickness of the ice, and hence its pressure, is less at the lip of the sill, relieves the bed in its neighbourhood of wear. On the steeply sloping downhill side of the sill, on the other hand, conditions are such as to favour wear, for the sliding will be concentrated in the lowest layer of the ice. This is the explanation of the steps so often seen in glacier beds.

Dr. Orowan went on to discuss the problem of a tall column of ice standing on a rigid horizontal plane. If the column were sufficiently high and slender, its weight would cause flow to take place at the bottom, and it would subside to an equilibrium height. In the Greenland ice-cap conditions are different, because, owing to the great extent of the ice mass, the shear stress acting on the lower strata impedes the flow there and at the same time tends to initiate flow in the upper strata. By the use of a simple theory of the process, the yield stress of ice can be calculated from the known height and width of Greenland. The figure so calculated, which is of the order of $1 \mathrm{kgm} . / \mathrm{cm}^{2}$, is in agreement with the results of laboratory experiments. A warning is necessary, however, because even a slight slope (1:300) would be sufficient to explain the spreading without invoking any other influence.

In the general discussion which followed, Mr. W. V. Lewis expressed the pleasure felt by glaciologists and those concerned with the land forms produced by glaciers at the interest that physicists are beginning to show in the subject. The uplifting of the thrust planes at the ends of glaciers would naturally cause less grinding to occur there than elsewhere, and this explains very satisfactorily why glaciers erode hollows in their beds. The formation of the lakes which are such a striking feature of Alpine scenery is now no longer so mysterious. Answering a question by Sir Geoffrey Taylor, Mr. Lewis expressed the opinion that the remarkably regular series of curves seen on the surface of the Môr de Glace, of which Dr. Perutz had shown a slide, are the result of successive overthrusts which have been afterwards drawn out into curves by the general flow of the ice. Several speakers referred to the slides Mr. Lewis presented, which showed the striking way in which large rocks and other debris, which had originally fallen into the Bergschrund at the head of the glacier, are later brought up to the surface on thrust planes lower down, and Mr. Webster Smith suggested an experiment in which coloured objects were to be carried down underneath the glacier. Dr. Perutz, however, thought that the slowness of the flow would make the experiment impossible. Mr. Webster Smith also emphasized the important influence of the varying hardness of the rocks constituting the glacier bed.

Dr. C. H. Desch drew a distinction between ice and metals by pointing out that, whereas ice expands on freezing, metals in general contract. That difference in behaviour should not be overlooked, and he suggested the use of bismuth at a few degrees below 
its melting point for laboratory experiments. Bismuth, although brittle under certain conditions, can be extruded and, in addition, expands on freezing; the analogy with ice is therefore complete.

Mr. C. Gurney took up this point later by saying that, whereas the effect of hydrostatic pressure on the melting point is of opposite sign for ice and metals, the effect of uniaxial compression is always to lower the melting point, even in metals.

In reply to Dr. G. W. Scott Blair's suggestion that ice might be found to behave more like a Bingham solid than a material obeying St. Venant's law of plasticity, Dr. Orowan said that the existence of transient creep is evidence that ice is not a Bingham solid; on the other hand, the existence of creep in general shows that it does not exactly obey St. Venant's law either.

Dr. Perutz had observed that in Alpine glaciers the crevasses were never more than about $30 \mathrm{~m}$. deep, and Mr. W. H. Ward pointed out that this depth could be correlated in order of magnitude with the known yield stress of ice.

The discussion provided a happy illustration of the benefit of applying the simplest of physical reasoning to a science as yet largely empirical. In the words of one of the contributors, it was "better to think exactly with simplified ideas than to reason inexactly with complex ones".

J. F. NYE

\section{PROGRESS IN ARTIFICIAL ILLUMINATION}

A LTHOUGH lip-service is commonly paid to the value of research, it is seldom that its direct benefits are so attractively displayed to the general public as has been done in the "Darkness into Daylight" Exhibition at the Science Museum, London, S.W.7. A visit to the Exhibition reminds one how very primitive were the means of artificial illumination only two centuries ago, while less than one hundred years ago the oil lamp was still the common form of lighting. We are all of us aware of the progress and achievements made during the past century. But how many realize that since only 1921 the efficiency of the ordinary 60 -watt electric lamp has increased by 55 per cent while the cost has decreased by 75 per cent.

The exhibition has been organised by the Science Museum with the co-operation of the electrical industry of Britain, mainly to set forth the story of the development of electric lighting, but also to give a lead, and an example of the form of artificial illumination in the future.

A brief introductory section includes examples of some of the primitive forms of lighting used by early man-a hollow stone with fibre burning in animal fat, a wicker-work cage of fire-flies, sea-shell and oyster-shell lamps, a burning fish and a wick threaded into the body of a stormy-petrel are typical examples.

Passing from these primitive forms of lighting, a brief survey of the stages from the Middle Ages to the nineteenth century is made in a series of dioramas, showing the gradual changes brought about as candles and tallow-dipped rushes gave place to oil lamps and then in turn to the gas lamps of the last century. We can see the dawn of electric lighting with Swan's invention of 1878, its temporary eclipse by the Welsbach incandescent gas mantle and then the final triumph of the electric filament lamp.
The filament lamp has had a long career, and since its invention by Swan in 1878 and Edison in 1879 it has passed through innumerable stages of development. Swan had spent many years of research before he produced his carbon filament in 1878 and, incidentally, he laid the foundation stone of the rayon industry by his subsequent development of the squirted nitrocellulose filament in 1883 . In stages, the carbon filament with its low efficiency of 2-3 lumens per watt gave way, first to the osmium filament, then to tantalum and finally to tungsten, when the difficulties of drawing tungsten wire had at last been overcome.

The tungsten-filament vacuum lamp had an efficiency nearly three times that of the carbon filament lamp, but to improve it still further a higher operating temperature was required. This resulted in an early blackening of the bulb, and although this could be overcome by filling the bulb with an inert gas, the heat lost by convection more than compensated for the gain until Langmuir's invention of the coiled filament in 1913. Still higher efficiencies were obtainable from the 'coiled-coil' filament invented soon after, but manufacturing difficulties prevented its introduction until 1934 .

The efficiency of the modern filament lamp varies from the order of 12 lumens per watt for the smaller domestic sizes to about 25 lumens per watt for the largest projector lamps and, regarded as a source of artificial illumination, it must be agreed that the filament lamp is a remarkably cheap device. Indeed, as the visitor to the 'Darkness into Daylight' Exhibition is reminded at one stage, the average 60 -watt lamp will burn for 1,000 hours at a cost, including that of the bulb, of only about $8 s .4 d$.; but were he by some whim or fancy to select candles as an alternative illuminant, he would need no less than 25,000 of them to give the same level of illumination for the same period and he would find himself faced with a bill of about $£ 100$ !

As is perhaps inevitable, the accent of the Exhibition is on fluorescent lighting, and as one passes through this section one is forced to wonder whether the life of the filament lamp is doomed and whether it will eventually be replaced, like the oil lamp and the gas lamp before, by the low-pressure fluorescent tubes now being so widely used. Hitherto, these fluorescent lamps have only been available in lengths of 4 and $5 \mathrm{ft}$., but the recent announcement that 2 -ft. tubes of 20 - and 40-watt ratings will soon be introduced suggests a much wider application for domestic purposes. The fluorescence section of the Exhibition opens with a brief historical account of the discovery and developments which have contributed to the perfection of the modern tubes-the early observa. tions of fluorescence, the Becquerel lamp of 1867 in which fluorescent materials were exeited in a discharge tube, and the discovery in 1923 of a means of applying fluorescent materials to the walls of a mercury lamp. The stories of the search for a better colour spectrum, the first 'daylight' lamps and the finding of a single powder for producing a warmwhite light are told by subsequent exhibits.

In imagination one is encouraged by a variety of fluorescent exhibits to regard such lamps as the lighting of the future. For industrial and commercial applications this indeed appears inevitable, but in spite of the three-fold improvement in efficiency and in spite of the three-fold increase in the average life, it still seems likely that the higher initial installation costs will reprieve the filament lamp for many years for ordinary domestic purposes. 